\title{
AUGMENTED REALITY PENGENALAN OBJEK WISATA TAMAN MUMBUL SANGEH BERBASIS ANDROID
}

\author{
Kadek Agus Wirawan ${ }^{1}$, I Gede Harsemadi ${ }^{2}$, Ni Kadek Sukerti ${ }^{3}$ \\ ${ }^{123}$ Prodi Sistem Informasi, Fakultas Informasi dan Komputer, \\ ITB STIKOM Bali Jalan Raya \\ Puputan Renon No. 86 Denpasar, Bali, Indonesia tlp. (0361) 244445 fax: (0361) 264773 \\ Aguswira881@gmail.com,harsemadi@stikom-bali.ac.id,dektisamuh@gmail.com
}

\begin{abstract}
Mumbul Park Tourism Object is a tourist attraction located in Sangeh Village, Abiasemal District, Badung Regency. In Mumbul Park there are two temples named Pura Luhur Mumbul (Puru Ulun Siwi) and Pura Ulun Mumbul. In addition to the temple in the Mumbul Sangeh Park Tourism Object, there is a pengelukatan called Pancoran Solas and there is a pond (lake) with thousands of fish. The Mumbul Park Tourism Object has its own charm for tourists, but the lack of information regarding the Mumbul Sangeh Park Tourism Object makes not many people know about the tourist area. Therefore, we need an introduction media regarding the object of the Mumbul Sangeh park which is more modern with Android based Augmented Reality media. This application contains direct information about the history of the Mumbul Park Tourism Object, Pancoran Solas 3D Penglukatan Object, Ulun Danu Temple and the Queen Niang Sakti Statue, Videos and Photos of the introduction of Mumbul Park. The method used in this research is the MDLC (Multimedia Development Life Cycle) method and the $C$ \# programming language. The making of this application uses Unity3D, CorelDraw and Adobe Illustrator as the interface designer, Adobe Premiere to edit the introduction video. Based on the results of tests carried out using two testing methods, namely blackbox testing and questionnaires. This application is distributed via Google Drive..
\end{abstract}

Keywords-Mumbul Sangeh Park, Pancoran Solas, Ulun Danu Temple, Ratu Niang Sakti Statue, Augmented Reality, Android

\begin{abstract}
ABSTRAK
Objek Wisata Taman Mumbul merupakan sebuah objek wisata yang berlokasi di Desa Sangeh, Kecamatan Abiasemal, Kabupaten Badung. Pada Taman Mumbul terdapat dua pura yang bernama Pura Luhur Mumbul (Puru Ulun Siwi) dan Pura Ulun Mumbul. Selain terdapat pura pada Objek Wisata Taman Mumbul Sangeh ini terdapat tempat penglukatan yang bernama Pengelukatan Pancoran Solas dan terdapat sebuah kolam (danau) dengan ribuan ikannya. Objek Wisata Taman Mumbul mempunyai daya tarik tersendiri bagi wisatawan, akan tetapi kurangnya informasi mengenai Objek Wisata Taman Mumbul Sangeh ini membuat tidak banyak orang mengetahui kawasan wisata tersebut. Maka dari itu dalam diperlukan sebuah media pengenalan mengenai objek wsiata taman mumbul Sangeh yang lebih modern dengan media Augmented Reality berbasis android.
\end{abstract}


Dalam aplikasi ini berisikan informasi langsung mengenai sejarah Objek Wisata Taman Mumbul, Objek 3D Penglukatan Pancoran Solas, Pura Ulun Danu dan Patung Ratu Niang Sakti, Video dan Foto pengenalan Taman Mumbul. Metode yang digunakan pada penelitian ini adalah metode MDLC (Multimedia Development Life Cycle) dan Bahasa pemrograman C\#. Pembuatan aplikasi ini menggunakan Unity3D, software desain sebagai pembuat desain antar muka software edit video untuk mengedit video pengenalan. Berdasarkan hasil pengujian yang dilakukan menggunakan dua metode pengujian yaitu blackbox testing dan kuesioner. Aplikasi ini didistribusikan melalui Google Drive.

Kata Kunci-Taman Mumbul Sangeh, Pancoran Solas, Pura Ulun Danu, Patung Ratu Niang Sakti, Augmented Reality, Android.

\section{Pendahuluan}

Sumbangan sektor pariwisata terhadap pembangunan ekonomi nasional diukur melalui tolak ukur paling penting yaitu mengenai sumbangan pada neraca pembayaran, pendapatan nasional, penciptaan lapangan kerja serta sektor pariwisata lainnya [1]. Terdapat keistimewaan pada setiap tempat wisata begitu juga dengan Objek Wisata Taman Mumbul Sangeh, dengan daya tarik tersendiri bagi wisatawan. Kurangnya informasi mampu menghambat berkembangnya tempat wisata. Dokmentasi dalam bentuk gambar dan video yang terkait pada objek wisata juga tidak banyak ditemukan. Tempatnya cukup mampu menampung pertunjukan tarian dan kegiatan upacara keagamaan [2]. Salah satu media sebagai pendukung pariwisata untuk media promosi dengan digunakan Multimedia Augmented Reality. Merupakan bagian teknologi yang memberikan pengalaman antarmuka yang unik. Prinsipnya adalah menggabungkan antara objek virtual baik dua atau tiga dimensi melalui objek nyata langsung terlihat didepan kamera. Cara kerjanya dengan mengarahkan kamera smartphone pada gambar yang sudah diberi marker. Pada saat marker telah berhasil teridentifikasi, maka aplikasi akan merender objek 2 dimensi maupun 3 dimensi, kemudian menampilkannya pada layar kamera dan objek yang dirender bisa dilihat dari berbagai arah. Gabungan antara buku biasa dengan teknologi Reality Augmented dinamakan Augmented Reality Book. Memiliki dua komponen utama, diantaranya buku dengan marker bertipe Quick Respone Code dan peralatan untuk menangkap marker dengan tujuan menampikan hasilnya. Merupakan media karena berbentuk bahan cetakan yang berisi marker sebagai target untuk menampillkan objek 3D [3]. Variasi dari virtual 
Environment dan lebih dikenal dengan Virtual Reality [4]. Untuk mempercepat link ke website, dial cepat untuk nomor telepon, dan mempercepat pengiriman SMS bisa memanfaatkan Quick Respone [5]. Penerapan ke beberapa aplikasi mobile kedalam kedua platform dapat menggunakan SDK Vuforia [6].

Berdasarkan permasalahan yang terdapat pada latar belakang, penulis berharap dapat memberikan informasi tentang pengenalan Objek Wisata Taman Mumbul Sangeh untuk semua masyarakat melalui media Augmented Reality, maka penulis mengusulkan judul proposal tugas akhir dengan judul "Augmented Reality Pengenalan Objek Wisata Taman Mumbul Sangeh Berbasis Android”.

\section{Metode Penelitian}

Metode system dirancang menngunakan metode Multimedia Developmet Life Cycle (MDLC). Terdiri dari 6 tahapan antara lain konsep, desain, material collecting, assembly, testing dan distribution. Pada tahapan konsep terdapat penentuan dari tujuan aplikasi ini. Perancangan dilakukan agar proses spesifikasi perancangan aplikasi dapat dijabarkan secara detail. Dan ini meruakan alur kerja aplikasi Augmented Reality [7]. Penggambaran manual dengan storyboard untuk rangkaian cerita atau deskripsi setiap scene agar mudah dipahami oleh pengguna, mencantumkan semua objek multimedia dan tautan ke scene lain [8].

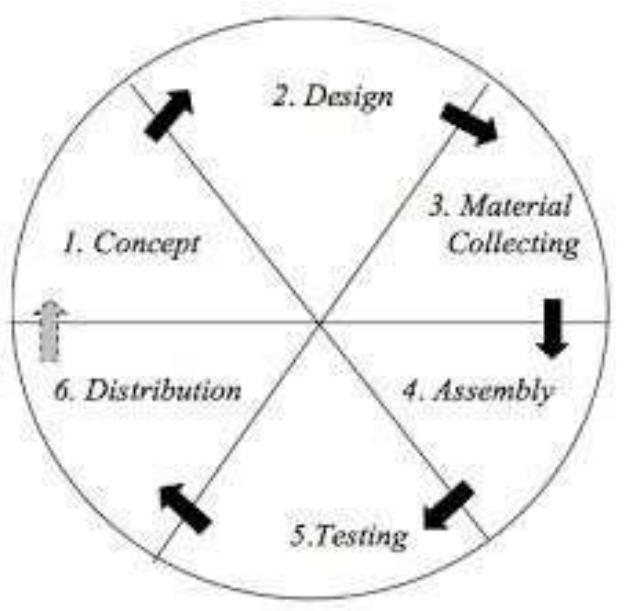

Gambar 1. Metode Pengembangan MDLC

Pada tahap penyebarluasan terdaat kegiatan kompresi jika terdapat situasi tidak cukupnya media penyimpanan untuk menampung seluruh aplikasi yang berjalan [9]. Dengan bantuan penyimpanan seperti Google Drive, Dropbox. Class diagram dari aplikasi pengenalan maskot Si Bangun dan Cana berbasis augmented reality. Dimana di dalamnya terdapat penjabaran dari masing-masing proses dari splash screen, main menu, menu Sejarah, Menu Pindai Kamera, menu Galeri dan menu tentang aplikasi. Sangat diperlukan pada tahap pengembangan produk yang telah dibuat sehingga lebih baik melalui proses evaluasi [10]. 


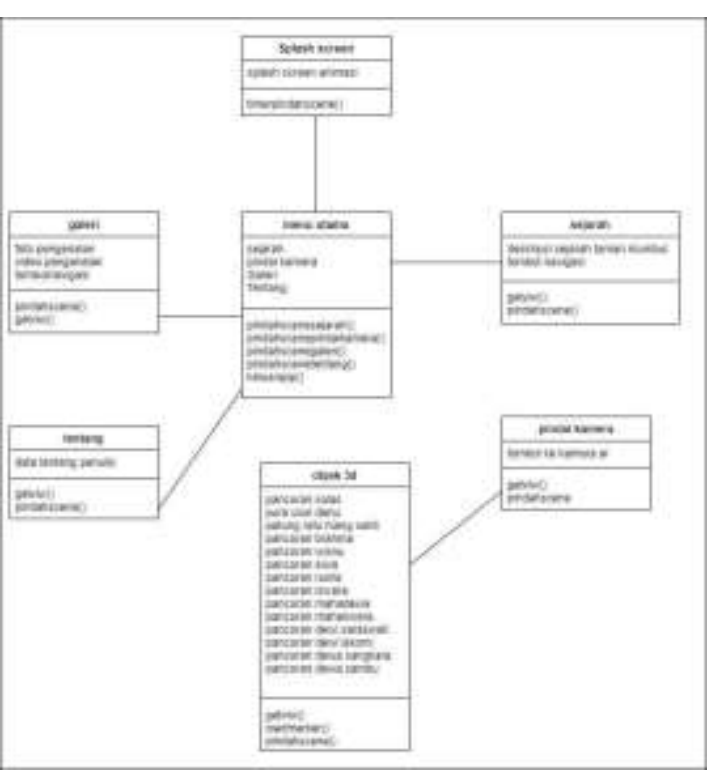

Gambar 2. Class Diagram

\section{Hasil dan Pembahasan}

Aplikasi yang telah dibangun memberikan hasil dimana yang baik tentang penjelasan tombol, fungsi dan deskripsi dari masing masing halaman atau scene pada aplikasi Augmented Reality Pengenalan Objek Wisata Taman Mumbul Sangeh Berbasis Android. Pada bagian menu utama terdapat 4 tombol menu utama yang disajikan pada bagian kiri halaman, judul pada bagain atas halaman dan tombol untuk play dan mute musik dibagian bawah, tombol petunjuk dibagian kanan bawah halaman serta tombol untuk keluar dari aplikasi dibagian atas.

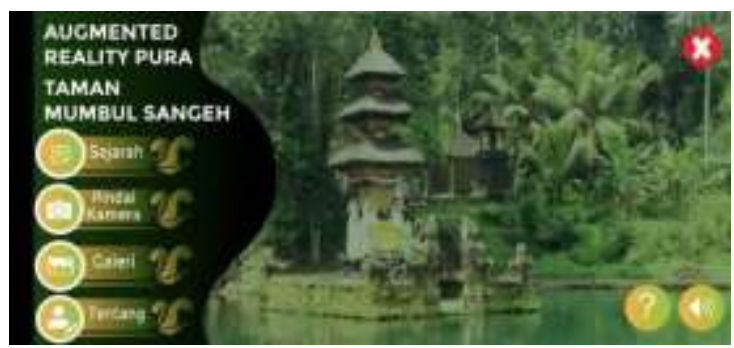

Gambar 3. Antarmuka Menu Utama
Pada menu Pindai Kamera user akan diarahkan ke halaman menu Pindai Kamera setelah menekan tombol Pindai Kamera user akan diarahkan ke halaman kamera AR yang dimana user akan diminta untuk megarahkan kamera ke marker yang sudah tersedia. Selanjutnya pada menu ini user dapat berinteraksi dengan objek 3 dimensi seperti memutar objek dengan tombol merubah ukuran objek dengan menekan tombol + atau dan membuka menu informasi dan tombol dubbing Menu Galeri.

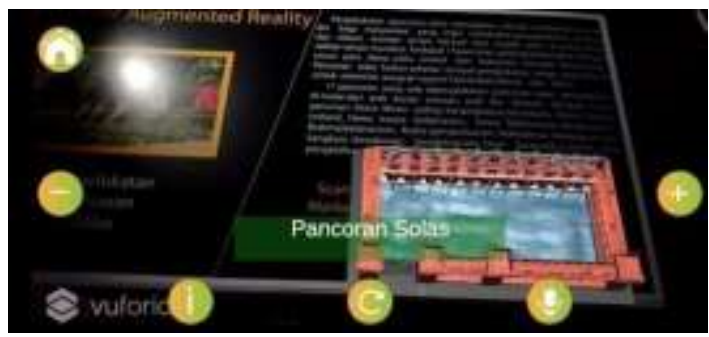

Gambar 4. Antarmuka Menu Pindai Kamera Objek 3D Pancoran Solas

Pada implementasi marker ditampilkan hasil desain marker yan digunakan, dimana pada aplikasi ini marker berfungsi sebagai penanda pada aplikasi dalam memunculkan objek 3 dimensi. Pada aplikasi ini penulis menggunakan marker book sebagai media marker pada aplikasi ini. Berikut adalah desain dari marker book yang penulis rancang: Pada bagian cover terdapat judul dari marker book untuk aplikasi pengenalan Objek Wisata Taman Mumbul Sangeh. 


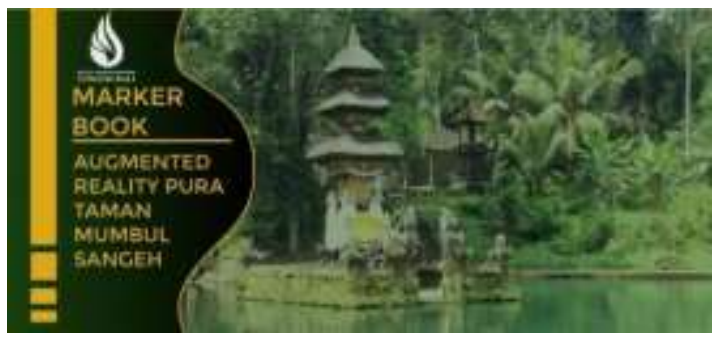

Gambar 5. Desain Cover Marker Book

Pada bagian deskripsi sejarah ini terdapat informasi mengenai sejarah dari Objek Wisata Taman Mumbul Sangeh.

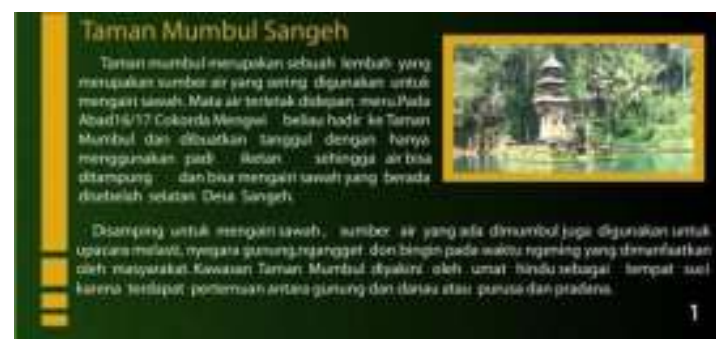

Gambar 6. Desain Deskripsi Sejarah Objek Wisata Taman Mumbul Sangeh

Penyebarluasan aplikasi maupun marker akan dilakukan melalui melalui link google drive dan link akan langsung terhubung ke penyimpanan google drive yang dimana menyimpan file aplikasi .apk. Aplikasi dan Marker dapat diunduh pada alamat link:

https://drive.google.com/folderview?id=1 ANgTn6GUstR2kZZ9DNBsOl 1-N-

\section{GdMofl}

\section{SiMPULAN}

Kesimpulan dari aplikasi yang telah dibangun, antara lain:

1. Menggunakan media berupa perangkat lunak Unity 3D, Blender 2.8, Adobe
Photoshop, Adobe Premiere, CorelDraw, dan Vuforia, untuk memperkenalkan Objek Wisata Taman Mumbul Sangeh.

2. Terdapat 4 menu yaitu, Sejarah Taman Mumbul, Pindai Kamera, Galeri, dan Tentang. Total objek yang terdapat pada aplikasi augmented reality ini berjumlah 3. Pada hasil pengujian kuesioner didapatkan hasil keseluruhan rata-rata nilai yaitu 3,4 dengan hasil persentase $85 \%$ dan dapat disimpulkan bahwa aplikasi ini termasuk kategori sangat setuju.

\section{DAFTAR PUSTAKA}

[1] Ni Putu Ayu Sucahya Dewi, Aplikasi Multimedia Pengenalan Objek Wisata Taman Mumbul Sangeh Berbasis Android. Denpasar; STIMIK STIKOM BALI.2020

[2] Beoang, Dean Dionisius, and Ida Ayu Suryasih. "Identifikasi Potensi Desa Wisata Sangeh, Kabupaten Badung”.

[3] I Nyoman Eva Surya Diana, Media Pengenalan Maskot Si Bangun Dan Cana Pada BAPPEDA Provinsi Bali Berbasis Augmented Reality.

Denpasar; ITB STIKOM BALI.2020

[4] Nugroho, Atmoko, and Basworo Ardi

Pramono. "Aplikasi Mobile Augmented Reality Berbasis Vuforia Dan Unity Pada Pengenalan Objek 3d Dengan Studi Kasus Gedung $M$ 
Universitas Semarang." Jurnal Transformatika 14.2 (2017): 86-91
Riset dan Observasi Sistem Komputer 3.2 (2016).

[5] A.A Ngurah Wisnu Widnyana, Aplikasi Augmented Reality Pura Alas Kedaton Berbasis Android. Denpasar; ITB STIKOM BALI. 2020.

[6] I Gede Putu Surya Gunawan, Aplikasi Pengenalan Barong Landung Pada Museum Bali Berbasis Augmented Reality. Denpasar; ITB STIKOM BALI. 2020.

[7] Yudi Prasetya, Augmented Reality Pengenalan Ciri-Ciri Pecandu Narkoba Berbasis Flatform Android. Denpasar; STIMIK STIKOM BALI. 2020.

[8] I Wayan Trisna Gunawan, Pengenalan Permainan Olahraga Bola Voli Untuk Siswa Sekolah Dasar Berbasis Augmented Reality. Denpasar; ITB STIKOM BALI. 2020.

[9] MZ, MM Komarudin. "Pengujian perangkat lunak metode black-box berbasis equivalence partitions pada aplikasi sistem informasi sekolah." MIKROTIK: Jurnal Manajemen Informatika 6.1 (2016).

[10] Nurajizah, Siti. "Implementasi Multimedia Development Life Cycle Pada Aplikasi Pengenalan Lagu AnakAnak Berbasis Multimedia." PROSISKO: Jurnal Pengembangan 